Trauma Surgery $\&$ Acute Care Open

\title{
Novel application of an old technique: the use of external to internal carotid artery transposition in trauma
}

\author{
Abbie May Jensen, James W Dennis, Jon C Allmon, Joseph H Habib, David J Skarupa
}

Department of Surgery, University of Florida College of Medicine, Jacksonville, Florida, USA

Correspondence to Dr David J Skarupa; david. skarupa@jax.ufl.edu

This case was presented at the Southeastern Surgical Congress as an ePoster presentation in Tampa, Florida, on February 12, 2018.

Received 20 March 2018 Accepted 30 March 2018

\footnotetext{
To cite: Jensen $A M$, Dennis JW, Allmon JC, et al. Trauma Surg Acute Care Open 2018:3:e000182.
}

A 27-year-old male patient presented to the Trauma Center with multiple gunshot wounds, including a wound to right zone II of the neck, three wounds to the posterior neck and intraoral wounds to the left soft palate. There was an associated expanding hematoma with pulsatile bleeding of the zone II neck wound and the patient was demonstrating lateralizing signs. Pressure was held to control bleeding and after completion of primary and secondary surveys the patient was transported to the operating room for exploration.

On induction of general anesthesia, an incision was made along the anterior border of the sternocleidomastoid muscle and carried down to the common carotid artery, and the vessel loop was encircled around it. There was active arterial and venous bleeding distally so the incision was extended and dissection was carried down to the internal jugular vein, which had an approximately $1 \mathrm{~cm}$, near-circumferential defect in it and was ligated.

The internal carotid artery (ICA) was then further dissected up to the level of the injury, which was approximately $1.5 \mathrm{~cm}$ distal to the carotid bifurcation. Arterial bleeding from the ICA was temporarily controlled by digital pressure while distal control

A

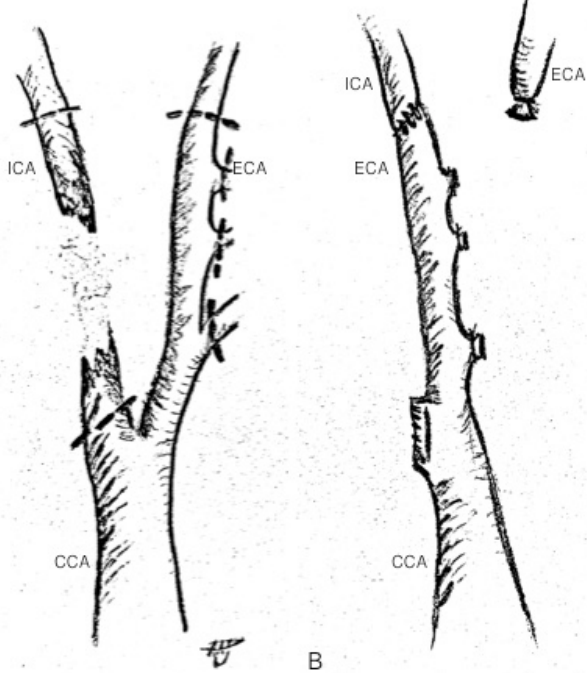

Figure 1 To the left $(\mathbf{A})$ is shown a damaged internal carotid artery (ICA), which is ligated proximally and distally. The external carotid artery (ECA) is dissected to its proper length, ligated distally, transposed and anastomosed in an oblique, end-to-end fashion to the distal ICA as seen on the right (B). Common carotid artery (CCA) was obtained of the ICA and external carotid artery (ECA) using vessel loops. There was a throughand-through injury to the ICA with significant blast effect requiring debridement of an approximately $4.0 \mathrm{~cm}$ segment with the proximal aspect just distal to the carotid bulb. Given the size and location of the injury, neither the use of an intraluminal shunt to preserve cerebral blood flow or primary repair of the damaged artery was feasible.

\section{WHAT WOULD YOU DO?}

A. Interposition grafting with native non-reversed greater saphenous vein.

B. Interposition grafting polytetrafluoroethylene (PTFE).

C. External to internal carotid artery transposition.

D. Ligation.

\section{WHAT WE DID AND WHY}

Correct answer: $\mathrm{C}$

Since the ECA was of sufficient size, it was mobilized and the side branches were ligated. The ECA was then ligated distally and the proximal end was beveled to facilitate an end-to-end anastomosis between the proximal ECA and the distal segment of the ICA using 6-0 Prolene (figure 1). All blood and debris was removed from the system, and the clamps were released allowing good antegrade blood flow. An exploration of the remainder of the neck was negative and incision was closed.

Immediately postoperatively, the patient underwent further imaging to rule out concomitant injury



Figure $2 \mathrm{CT}$ angiography on postoperative day 0 of the right neck demonstrating a patent external to internal carotid anastomosis with no flow-limiting stenosis to the intracranial circulation. The adjacent internal jugular vein is ligated. 


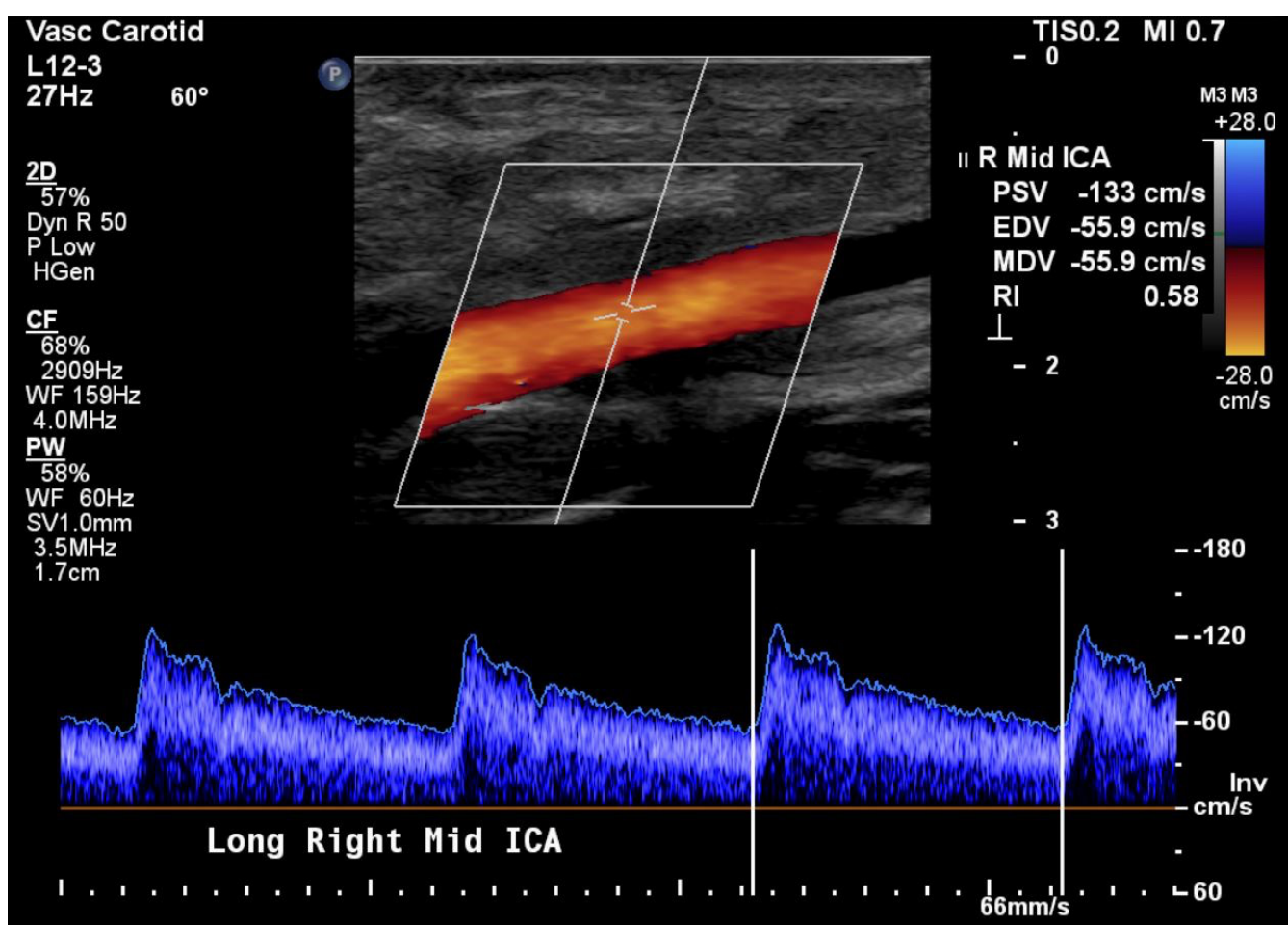

Figure 3 Carotid duplex ultrasonography at 60 days post-op showing a patent anastomosis without flow-limiting stenosis. ICA, internal carotid artery.

due to unclear trajectory of multiple gunshot wounds. CT angiography (figure 2) demonstrated a patent anastomosis and no injury to the aerodigestive tract except for a complex wound of the oropharynx requiring a tracheostomy for airway control and multiple debridements. During his subsequent 24-day hospital course, the patient returned to his neurologic baseline without residual deficits. His tracheostomy was decannulated prior to his discharge to a rehabilitation facility. Subsequent outpatient follow-up 60 days postoperatively revealed the patient to be in excellent condition without neurologic deficit. Carotid ultrasound showed no flow-limiting stenosis (figure 3 ). The patient remained on aspirin $325 \mathrm{mg}$ daily for 6 months postoperatively.

ECA transposition with ligation of distal ECA and end-to-end ECA to ICA anastomosis has been described in management of non-traumatic ICA pathology, including age-related occlusive disease and repair of ICA aneurysms. However, this technique has not been reported for revascularization of the ICA in penetrating trauma. Transposition is an attractive option for several reasons. It eliminates the need for saphenous vein harvest and requires only a single anastomosis, effectively cutting operative time and insult to the patient. Transposition uses only autologous tissue, removing the added risk of using a synthetic material in a potentially contaminated traumatic wound. Lastly, it mitigates the need for lifelong antiplatelet therapy as would be recommended after reconstruction with an interposition vein conduit or prosthetic graft.

Complications related to ECA ligation are rare, owing to collateral circulation provided by the contralateral ECA and the Circle of Willis. One technical consideration of ECA to ICA transposition is that the injury must be at the level of the proximal ICA to have adequate ECA length to reach the distal stump of the ligated ICA. Additionally, size discrepancy between the ECA and ICA can be reconciled by spatulating the artery or performing an oblique end-to-end anastomosis such as was done in this case.

In conclusion, ECA to ICA transposition offers a reasonable reconstructive option in select cases of zone II ICA injury, particularly when the extent of the arterial damage precludes primary repair. It could be considered superior to autologous or synthetic grafting in the right scenario.

Contributors AMJ and JWD were involved in direct patient care as pertains to this case. AMJ, DJS and JWD participated in article writing. DJS, JCA and JHH contributed to critical revisions.

Funding The authors have not declared a specific grant for this research from any funding agency in the public, commercial or not-for-profit sectors.

Competing interests None declared

Patient consent Not required

Provenance and peer review Not commissioned; externally peer reviewed. Data sharing statement There are no unpublished data to report.

Open Access This is an Open Access article distributed in accordance with the Creative Commons Attribution Non Commercial (CC BY-NC 4.0) license, which permits others to distribute, remix, adapt, build upon this work non-commercially, and license their derivative works on different terms, provided the original work is properly cited and the use is non-commercial. See: http://creativecommons.org/ licenses/by-nc/4.0/

(C) Article author(s) (or their employer(s) unless otherwise stated in the text of the article) 2018. All rights reserved. No commercial use is permitted unless otherwise expressly granted. 